\title{
The Influence of Carbonate Ions on the Structure of the Electrical Double Layer at the Interface of Hydroxyapatite/Electrolyte Solution
}

\author{
Ewa SKWAREK*, Władysław JANUSZ \\ Faculty of Chemistry, Maria Curie-Skłodowska University, pl. Maria Curie-Skłodowskiej 3, 20-031 Lublin, Poland \\ cross $^{\text {ref }}$ http://dx.doi.org/10.5755/j01.ms.22.2.7817
}

Received 24 August 2014; accepted 17 May 2015

\begin{abstract}
The aim of the work was to investigate the changes in the double electrical layer at the hydroxyapatite containing different amount of carbonate ions/electrolyte solution. Besides, the main properties of the edl (electrical double layer), i.e. surface charge density and zeta potential were determined by electrophoresis measurements and potentiometer titration, respectively. The synthesized adsorbents were characterized by the following methods: X-ray diffraction, FTIR (Fourier Transform Infrared Spectroscopy), adsorption and desorption of nitrogen and scanning electron microscopy. The analyzed samples had different structures and particle sizes. It was proved that increase in the carbonate groups content is connected with the decrease of apatite grain sizes and crystallinity reduction. The characteristic parameters of the electric double layer were also different: $\mathrm{pH}_{\mathrm{pzc}}$ (point zero of charge) of hydroxyapatite was 6.5 whereas for carbonate apatite was higher $-\mathrm{pH}_{\mathrm{pzc}}=8$. In both cases determination of precise $\mathrm{pH}_{\mathrm{IEP}}$ (isoelectric point) was not possible but it is known that its value is lower than 4 .
\end{abstract}

Keywords: hydroxyapatite, electrical double layer, pHpzc, pHiep, carbonates ions.

\section{INTRODUCTION}

Lately some attempts have been made to find materials for safe filling of bone losses. One of them is hydroxyapatite. These biomaterials prove to be effective as implants and are widely applied in injury and reconstruction surgery. Modern medicine is oriented at improvement of hydroxyapatite materials by making them similar to natural tissues. This effect can be achieved by introducing the $\mathrm{CO}_{3}{ }^{2-}$ ions admixtures into the hydroxyapatite structure. The formed carbon apatites are a promising alternative for implants made of pure hydroxyapatite. Therefore, it is of significant importance to get to know their properties and behaviour under in vitro and in vivo conditions. The term carbonate apatite refers to each apatite containing carbonate ions in their structure. Carbonate apatite differs from pure hydroxyapatite in chemical composition, stoichiometry, crystallinity as well as physicochemical and mechanical properties. $\mathrm{CO}_{3}{ }^{2-}$ groups incorporation into the spatial hydroxyapatite lattice results in the increase of its reactivity [1]. It was proved that increase in the carbonate groups content is dissolution extent increase [2]. Carbonate apatite is less chemically stable than stoichiometric hydroxyapatite. Nevertheless, it is believed that incorporation of carbonate ions into the hydroxyapatite structure is a potential way to make the obtained material similar to biological apatite. Thus, it is possible to achieve larger bioactivity and biocompatibility of hydroxyapatite ceramics. Owing to increased solubility and the effect on resorption, synthetic carbon apatites show promising possibilities of their application in medicine and stomatology [1, 3].

Carbonate apatite implants increase local concentration of calcium and phosphorus ions, which are

\footnotetext{
* Corresponding author. Tel.: +48 0815375622; fax: +48 0815332811.

E-mail address: ewunias@hektor.umcs.lublin.pl (E. Skwarek)
}

indispensable in bone remodelling [4]. Prominent osteoconductivity of carbon apatite is a result of microstructural and chemical similarity to mineral substance of bone tissue. The studies proved, that after application of carbon apatite implants, they were interbedded with Havers canals after a few weeks [2]. Structural defects in the carbonate apatite lattice, due to the presence of admixtures, can result in secondary bond formation between implanted material and various groups inside living cells. This affects significantly behaviour of hydroxyapatite material under the in vivo conditions. $\mathrm{S}$. Peroos [5] and co-workers used computer modelling techniques for qualitative and quantitative description of carbon group's penetration and arrangement of in them the spatial hydroxyapatite lattice. In the experiment different types of defects and different ways of charge compensation were taken into consideration. The simulations indicated that formation of each type carbon apatite is possible. Scientists' calculations shown, that type A of carbon apatite, where two $\mathrm{OH}^{-}$groups were replaced by a carbonate one in the hydroxyl canal, is the most stable defect structure. Formation of type B defect is also possible in the energetic aspect, depending on the way of charge compensation. The carbonate groups substitution in B-CA is energetically neutral; however, calancing of charge by inserting sodium and potassium ions into the lattice makes the system advantageous.

The work, which investigates the preparation of a carbonated apatite with a crystal size similar to biological apatites is by Garskaite, Gross et al. [6].

This paper deals with the issues connected with structure and properties of hydroxyapatite and carbonate apatite. The aim of the research was synthesis of hydroxyapatite powders of different $\mathrm{CO}_{3}{ }^{2-}$ ions contents and then studies of electrical double layer structure at the interface of the obtained samples and electrolyte solution. 


\section{EXPERIMENTAL}

The studies of hydroxyapatite and carbonate apatite obtained by the wet method were carried out [7]. In order to prepare reactions substrates there were made $1 \mathrm{M}$ solutions of the fallowing reagents: $\mathrm{Ca}(\mathrm{OH})_{2}$ calcium hydroxide $95 \%$ purity of the Aldrich, $\mathrm{H}_{3} \mathrm{PO}_{4}$ - ortophosphoric acid (V), 85\% purity of the POCh, $\mathrm{CaCO}_{3}$ calcium carbonate prepared in the Department of Radiochemistry and Colloid Chemistry. Hydroxyapatite powder was obtained by titration of $180 \mathrm{~cm}^{3}$ of hydroxide suspension with phosphoric acid (V) solution $\mathrm{pH}=9.2$. The procedure was repeated three times: on the average about $92 \mathrm{~cm}^{3}$ of $\mathrm{H}_{3} \mathrm{PO}_{4}$ was used. The analogous way was used to obtain HAP with incorporated carbonate groups. In this case acid was used for titration of $200 \mathrm{~cm}^{3}$ of equimolar $\mathrm{Ca}(\mathrm{OH})_{2}$ and $\mathrm{CaCO}_{3}$ mixture (calcium carbonate was used in order to facilitate keeping of $\mathrm{pH}$ value about 9 with hydroxyapatite precipitation which is the most effective. The obtained sediments were washed many times with redistilled water and centrifuged till the constant value of conductivity of the flushing solution was obtained and then dried at $80^{\circ} \mathrm{C}$ for $24 \mathrm{~h}$.

The zeta potential was measured using the Zetasizer 3000 apparatus produced by the Malvern. Before measuring the zeta potential there were prepared the aqueous $\mathrm{NaCl}$ solutions of the concentrations: $10^{-3} \mathrm{~mol} / \mathrm{dm}^{3}, 10^{-2} \mathrm{~mol} / \mathrm{dm}^{3}, 10^{-1} \mathrm{~mol} / \mathrm{dm}^{3}$.Then it was ultrasonificated in a Sonicator XL2020 produced by Misonix for 3 minutes to achieve complete dispersion of the sediment. The obtained suspension was poured into Erlenmeyer flasks. In the next stage the $\mathrm{pH}$ values: 5, 6, 7, $8,9,10$ and 11 of the suspension were established by dropping in $0.1 \mathrm{~mol} / \mathrm{dm}^{3}$ and $0.01 \mathrm{~mol} / \mathrm{dm}^{3} \mathrm{HCl}$ or $\mathrm{NaOH}$ solution. Then the zeta potential was measured using Malvern apparatus. In the same way the zeta potential of the suspension with the addition of $\mathrm{CO}_{3}{ }^{2-}$ ions of the concentrations $10^{-6}, 10^{-5}, 10^{-4}$ and $10^{-3} \mathrm{~mol} / \mathrm{dm}^{3}$ was measured.

To determine parameters of sample surface porous structure, the low temperature nitrogen adsorptiondesorption method was used. The measurements were made by means of the automatic adsorption analyzer of the ASAP 2405 type (Accelerated Surface Area and Porosimetry) by the Micromeritics Instruments, Co. The grain sizes were determined by means of the Mastersizer apparatus produced by Malvern. Hydroxyapatite of a determined specific surface area was characterized by $\mathrm{X}$ ray diffraction methods and scanning electron microscopes. The surface was characterized using a scanning transmission electron microscope S/TEM with the analysis EDX (Titan3 ${ }^{\mathrm{TM}} \mathrm{G} 2$ 60-300) (Table 1).

Comparing the photos at Fig. 1 by the scanning electron microscope of pure hydroxyapatite and hydroxyapatite with inbuilt carbonate ions, distinct differences can be seen. In both cases aggregates are formed but carbonate apatite grains have a smoother wall, which is probably caused by substitution of phosphate groups by carbonates in the crystal lattice of hydroxyl apatite and as a results of solubility increase. Formation of hydroxyapatite particles agglomerates can be explained by the mechanisms of nucleation, agglomeration growth proposed by Randolph and Larson as well as Rodriguez [8].

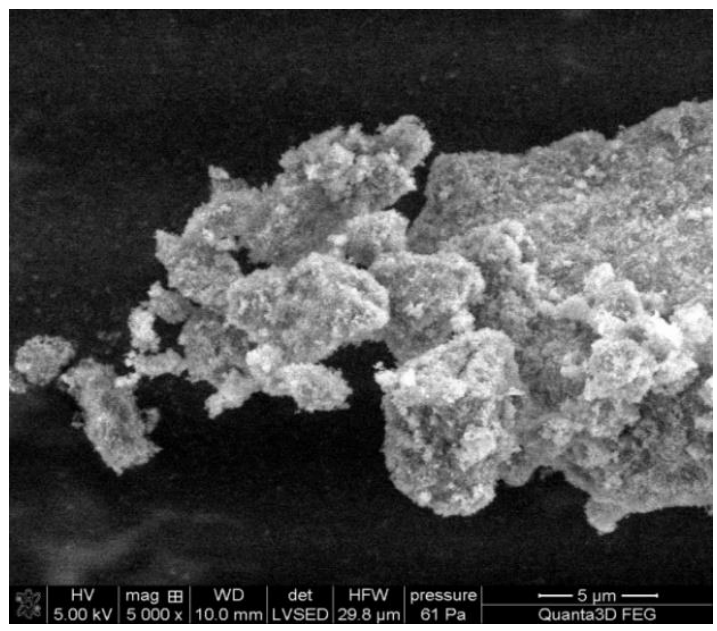

a

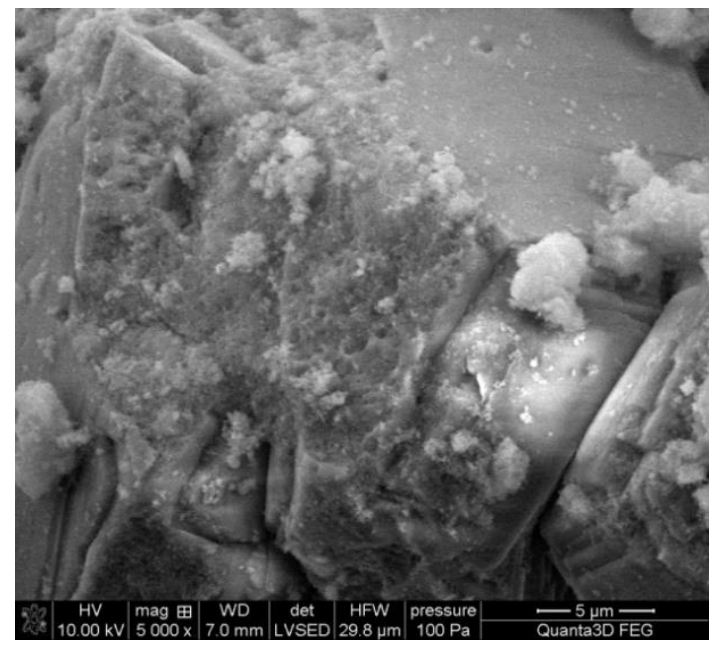

b

Fig. 1. $a-S / T E M$ picture of hydroxyapatite; b-carbonate apatite

Table 1. Percentage content of $\mathrm{Ca}$ and $\mathrm{P}$ in the samples

\begin{tabular}{|l|c|c|c|c|c|}
\hline \multirow{2}{*}{} & \multicolumn{2}{|c|}{ hydroxyapatite } & \multicolumn{3}{c|}{ hydroxyapatite / carbonate } \\
\cline { 2 - 6 } & $\mathrm{Ca}$ & $\mathrm{P}$ & $\mathrm{Ca}$ & $\mathrm{P}$ & $\mathrm{C}$ \\
\hline \% mass & 44.88 & 21.49 & 43.13 & 23.59 & 13.12 \\
\hline \% mass & 28.77 & 17.82 & 10.75 & 7.61 & 23.94 \\
\hline
\end{tabular}

X-ray diffraction was studied by means of the Empyrean diffractomer produced by PANalytical (lamp $\mathrm{Cu}$ LEF HR, detector pixel-3D, active channels 255).

Based on the comparison of the XRD diffraction patterns and the data library, in both cases there were found peaks characteristic of hydroxyapatite (at the angle 2 theta equal to 25.9, 32.96, 39.84, 49.5) (Fig. 2). Moreover, the secondary phase, which was calcium carbonate, was detected in carbonate apatite. The sample contained $72.3 \%$ of hydroxyapatite and $27.7 \%$ of calcium carbonate. The size of crystallites calculated from the results of X-ray diffraction, line profile (Rietveld reTirement) was $\mathrm{HAP}=18 \mathrm{~nm}, \mathrm{HAP}+$ carbonates $16.32 \mathrm{~nm}, \mathrm{CaCO}_{3} 276.8 \mathrm{~nm}$. Incorporation of carbonate ions in the crystal structure of hydroxyapatite caused insignificant decrease of crystallite size. As it can be seen from Table 2 both total volume, average radius of pores 
and specific surface area of the hydroxyapatite sample decreased after incorporation of carbonate ions.

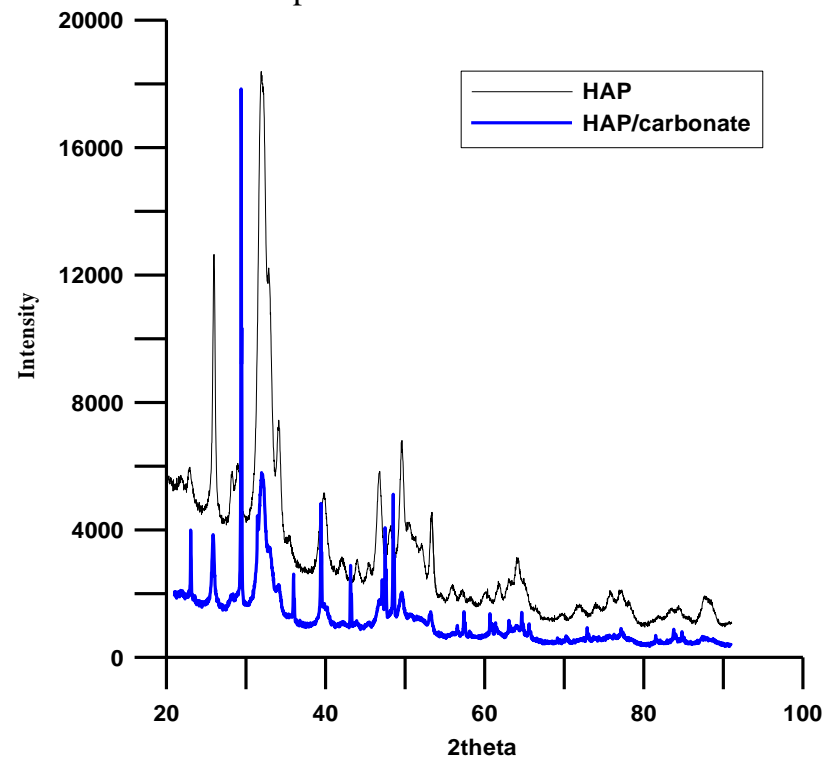

Fig. 2. XRD patterns of hydroxyapatite and carbonate apatite

Table 2. Chosen structural parameters

\begin{tabular}{|l|c|c|}
\hline & $\begin{array}{c}\text { Hydroxy- } \\
\text { apatite }\end{array}$ & $\begin{array}{c}\text { Hydroxyapatie/ } \\
\text { carbonate }\end{array}$ \\
\hline BET surface area, $\mathrm{m}^{2} / \mathrm{g}$ & 79.22 & 43.6 \\
\hline Langmuir surface area, $\mathrm{m}^{2} / \mathrm{g}$ & 116.27 & 65.71 \\
\hline $\begin{array}{l}\text { BJH cumulative adsorption } \\
\text { surface area of pores } \\
\text { between } 1.7 \text { and } 300 \mathrm{~nm} \\
\text { diameter, } \mathrm{cm}^{3} / \mathrm{g}\end{array}$ & 0.58 & 0.27 \\
\hline $\begin{array}{l}\text { BJH cumulative desorption } \\
\text { surface area of pores } \\
\text { between } 1.7 \text { and } 300 \mathrm{~nm} \\
\text { diameter, } \mathrm{cm}^{3} / \mathrm{g}\end{array}$ & 0.59 & 0.27 \\
\hline $\begin{array}{l}\text { Average pore diameter } \\
\text { (4V/A by BET), nm }\end{array}$ & 29.65 & 24.40 \\
\hline $\begin{array}{l}\text { BJH adsorption on average } \\
\text { pore diameter (4V/A), nm }\end{array}$ & 31.72 & 24.87 \\
\hline $\begin{array}{l}\text { BJH desorption on average } \\
\text { pore diameter (4V/A), nm }\end{array}$ & 29.63 & 23.53 \\
\hline
\end{tabular}

These phenomena can be explained by plugging pores with relatively large carbonate ions. Decrease in the specific surface area in case of the $\mathrm{HAP} / \mathrm{CO}_{3}$ sample can be caused by lower $\mathrm{pH}$ in the initial stage of synthesis as more acidic conditions promote formation of hydroxyapatite of less developed surface architecture. The sample containing carbonate apatite is characterized by smaller average grain sizes. This difference is particularly distinct in water dispersion $(593.794 \mu \mathrm{m}$ for the sample $\mathrm{HAP}$ and $32.384 \mu \mathrm{m}$ for $\mathrm{HAP} / \mathrm{CO}_{3}$. In the electrolyte solution the average molecule size of both materials is similar $(59.074 \mu \mathrm{m}$ for the sample HAP and $36.283 \mu \mathrm{m}$ for $\mathrm{HAP} / \mathrm{CO}_{3}$ though carbonate apatite exhibits disintegration as before. Calcium carbonate particles are much smaller than those of both synthesized compounds so it can be concluded that carbonate ions are incorporated into the crystal structure of hydroxyapatite. The presence of electrolyte increases insignificantly grain sizes in the samples of calcium carbonate and apatite with incorporated carbonate ions and in the case of hydroxyapatite results in grain sizes decrease. Ultrasonification of both water and with the addition of $\mathrm{NaCl}$ samples resulted in fragmentation of particle agglomerates into smaller ones. Fragmentation increased with longer time of ultrasounds action. However, it was not possible to obtain the size of sediment particles visible in the microscopic magnification. Brunauer, Emmett and Teller (BET) theory and specific surface area determination and BJH (BarretJoyner-Halenda) method cumulative adsorption/desorption pore volume were used in the experiment.

\section{RESULTS AND DISCUSSION}

Spectra of the samples differ distinctly one from another. At Fig. 3 on both of them 3 bands originating from stretching vibrations of the group $\mathrm{PO}_{4}$ (at 961, 600 and $577 \mathrm{~cm}^{-1}$ ) can be observed.
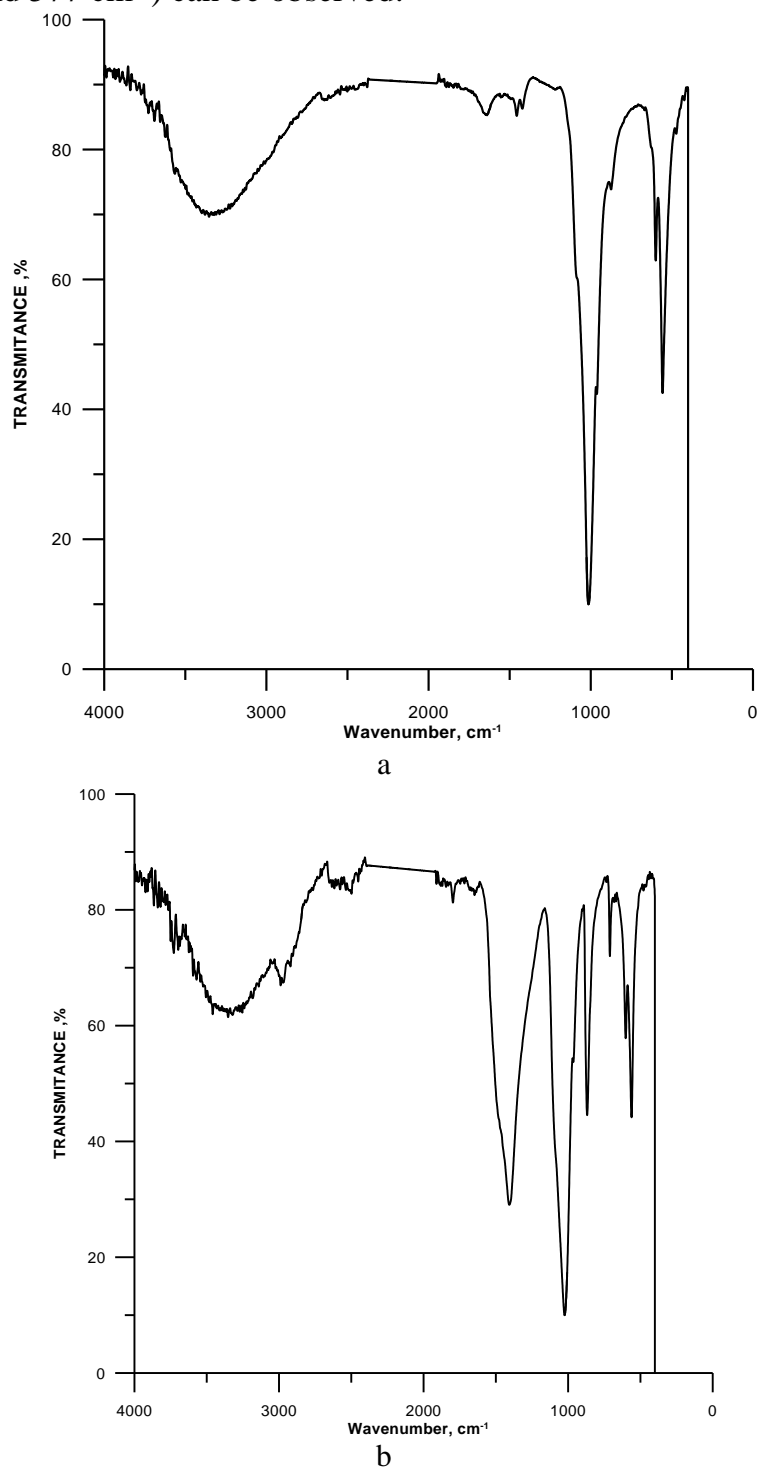

Fig. 3. Spectra of a-hydroxyapatite samples; $b$-carbonate apatite

The presence of $\mathrm{OH}^{-}$group is found at the frequency $3353 \mathrm{~cm}^{-1}$. A broad band in the frequency range $1400-1450 \mathrm{~cm}^{-1}$ can be seen on the spectrum of carbonate apatite. It is a result of superimposition of the components of the doublet coming from the asymmetric stretching vibration $\mathrm{C}=\mathrm{O}$ of carbonate ions. The presence of the $\mathrm{CO}_{3}$ 
group is also confirmed by the band at the frequency $876 \mathrm{~cm}^{-1}$ corresponding to the out of the plane bending vibration. From the band position it can be assumed that carbonate apatite of B type was obtained. This is in agreement with the literature data about the effect of choosing the synthesis method on localization $\mathrm{CO}_{3}{ }^{2-}$ ions admix times. The vibrations characteristic for carbonate groups are also visible on the spectrum of hydroxyapatite sample $\left(1456,1421\right.$ and $\left.876 \mathrm{~cm}^{-1}\right)$.

Their intensity is not large, which indicates small concentration of HAP with carbonate groups. Incorporation of $\mathrm{CO}_{3}{ }^{2-}$ ions took place probably in the stage of washing or drying samples and could be caused by adsorption of carbon dioxide from the air. On the spectrum of the sample $\mathrm{HAP} / \mathrm{CO}_{3}$ there can be also seen the band of the frequency $700 \mathrm{~cm}^{-1}$. This corresponds to vibrations of $\mathrm{CO}_{3}$ ions originating from calcite, which according to the $\mathrm{XRD}$ analysis in formed as a secondary phase next to carbonate apatite.

Charge on the hydroxyapatite surface can be formed due to the reaction of surface groups with electrolyte ions and the unbalanced anion and cation adsorption. Because of the fact that hydroxyapatite is a salt of basic character, there will be two kinds of groups on the surface: hydroxyl and phosphate. It can be assumed that like in acids the $\mathrm{PO}_{4}{ }^{3-}$ groups have acidic character but the $\mathrm{OH}^{-}$groups the amphoteric one. The reactions leading to charge formation in aqueous solutions will proceed as follows:

$\equiv \mathrm{PO}_{4} \mathrm{H} \leftrightarrow \equiv \mathrm{PO}_{4}^{-}+\mathrm{H}^{+}$

$\equiv \mathrm{PO}_{4}^{-}+\mathrm{Ca}^{2+} \leftrightarrow \equiv \mathrm{Ca}^{2+}\left(\mathrm{PO}_{4}\right)^{-}$

$\equiv \mathrm{CaOH}+\mathrm{H}^{+} \leftrightarrow \equiv \mathrm{CaOH}_{2}{ }^{+}$;

$\equiv \mathrm{CaOH} \leftrightarrow \equiv \mathrm{CaO}^{-}+\mathrm{H}^{+}$;

$\equiv \mathrm{PO}_{4} \mathrm{H}+\mathrm{CO}_{3}{ }^{2-} \leftrightarrow \equiv \equiv \mathrm{PO}^{-}+\mathrm{HCO}_{3}^{-}$.

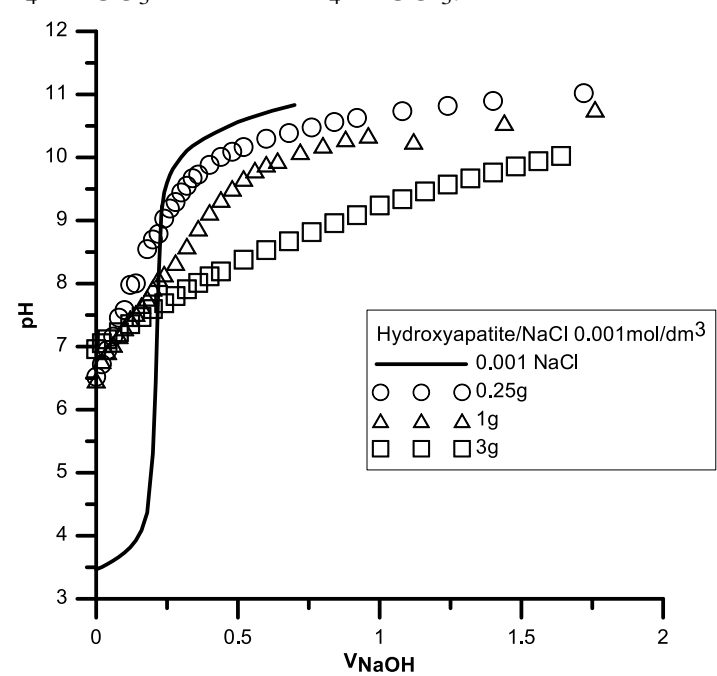

Fig. 4. Curves of potentiometric titration of the hydroxyapatite samples

The diagrams obtained for both samples differ significantly (Fig. 4 and Fig. 5). Intersection of titration curves of hydroxyapatite suspension corresponding to the pHpzc point occurs at $\mathrm{pH}=6.5$, which is in agreement with the literature data $[9,10,11]$. For the carbonate apatite sample pHpzc is higher and is 8, thus it is lower than for the $\mathrm{CaCO}_{3}$ sample which is about 9. Thus can be assumed that carbonate ions affect the surface charge.

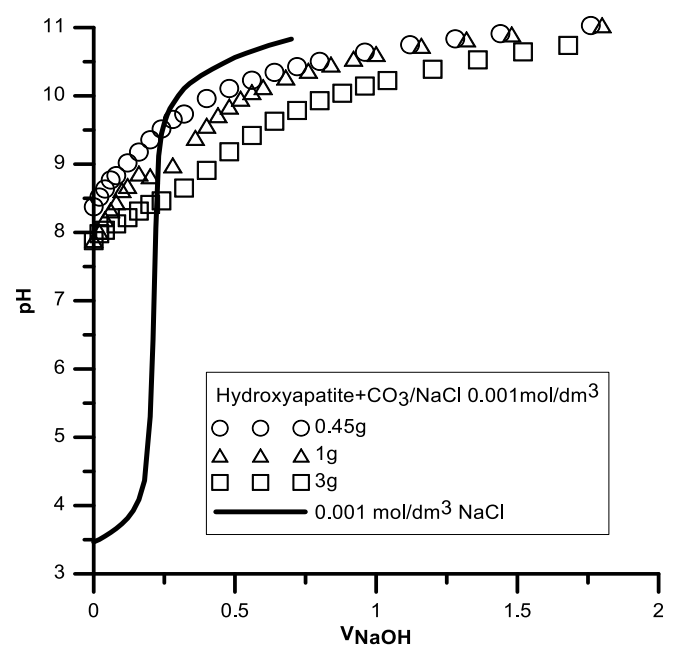

Fig. 5. Curves of potentiometric titration of the carbonate apatite samples

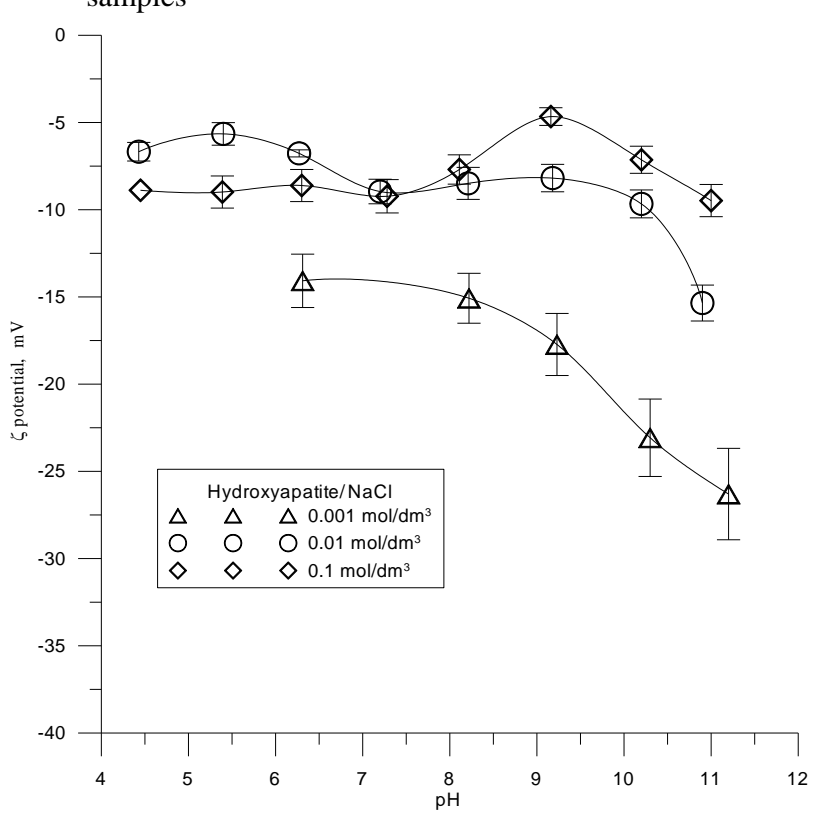

Fig. 6. Diagram of dependence of zeta potential on $\mathrm{pH}$ in the hydroxyapatite/electrolyte solution system

Zeta potential is negative in the whole $\mathrm{pH}$ range for both samples (Fig. 6 and Fig. 7). Its value is from $-5 \mathrm{mV}$ to $-30 \mathrm{mV}$ for hydroxyapatite and from $-5 \mathrm{mV}$ to $-13 \mathrm{mV}$ for carbonate apatite. As already mentioned, the negative value of the zeta potential is favourable for bone tissue deposition on the implants from CPS. The zeta potential in the samples of hydroxyapatite dispersed in the $\mathrm{NaCl}$ solutions of the concentration 0.1 and $0.001 \mathrm{M}$ is almost the same. In case of the sample with the lowest concentration electrolyte drop in $\zeta$ with the increasing $\mathrm{pH}$ was found. The same dependence is observed for the carbonate apatite samples in 0.01 and $0.001 \mathrm{~mol} / \mathrm{dm}^{3} \mathrm{NaCl}$. The dependence of zeta potential in the $\mathrm{pH}$ function indicates that $\mathrm{pH}_{\mathrm{IEP}}$ has the value $<4$ in both cases and thus it is lower than the value of pHpzc. This divergence is due to the fact of determination of surface charge density from the acidic basic surface groups (amphoteric hydroxyl ions and $\mathrm{PO}_{4}{ }^{3-}$ groups of acidic character). The zeta potential is also dependent on a part of surface charge affected by non -uniform absorption or desorption of calcium or phosphate ions. 


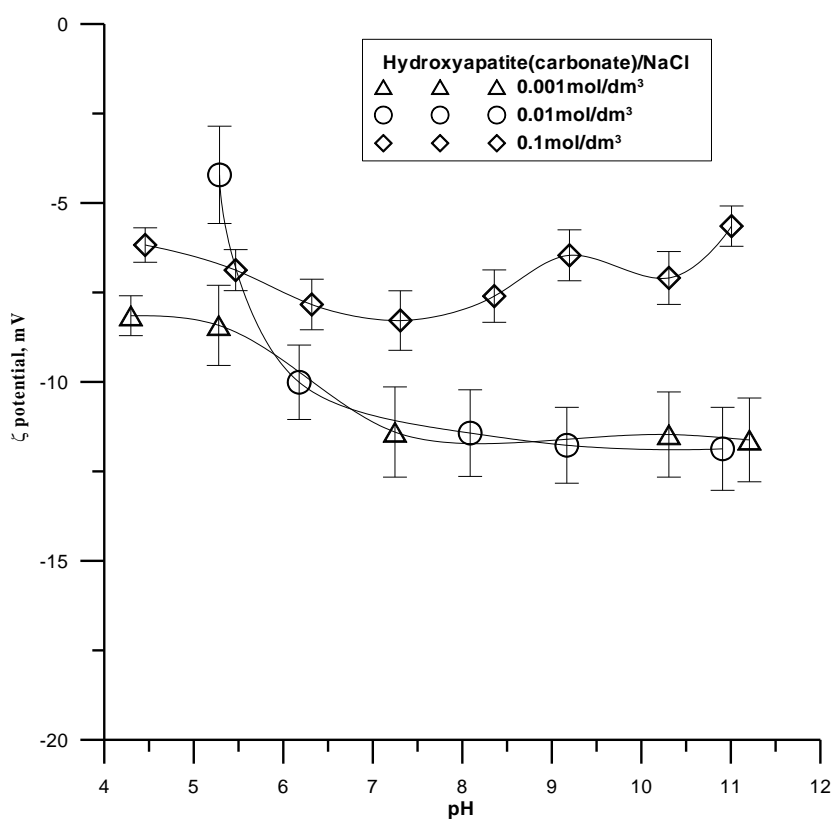

Fig. 7. Diagram of dependence of zeta potential on $\mathrm{pH}$ in the

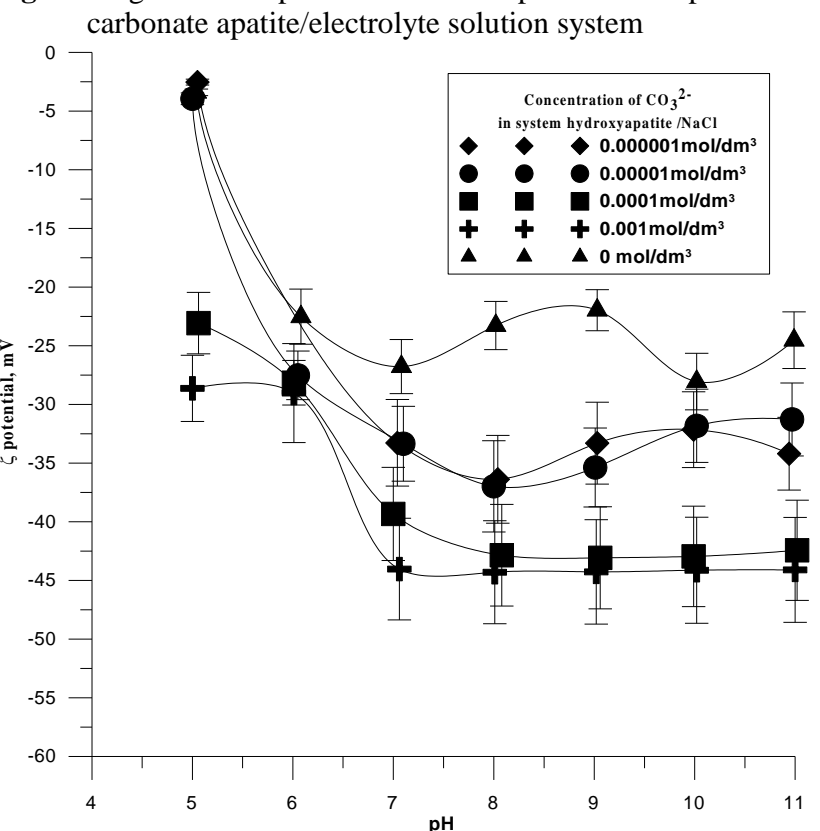

Fig. 8. Effect of carbonate ions adsorption on the dependence of $\zeta$ potential on $\mathrm{pH}$ in the hydroxyapatite $/ 0.001 \mathrm{~mol} / \mathrm{dm}^{3}$ $\mathrm{NaCl}$ solution

Effect of carbonate ions influence on the zeta potential is presented in Fig. 8. As it can be seen from the concentration $0.000001 \mathrm{~mol} / \mathrm{dm}^{3}$ drop in the value of potential $\zeta$ is visible which may be caused by increase of the negatively charged groups concentration on the hydroxyapatite surface. Carbonate ions replacing hydroxyl ions, change the character of hydroxyapatite surface, increasing its acidic character. This may be caused by formation of intraspherical complexes due to carbonates adsorption.

\section{CONCLUSIONS}

Carbonate ions substitution significantly affected the structure and properties of hydroxyapatite. The analysed samples (hydroxyapatite and carbonate hydroxyapatite) differed in structure and size of grains. It was proved that increase in the carbonate groups content is connected with the decrease of apatite grain sizes and crystallinity reduction. They also exhibited different values of parameters characterizing the double electrical layer $\mathrm{pHpzc}$ of hydroxyapatite was 6.5 but that of carbonate apatite was higher that is $\mathrm{pHpzc}=8$. In both cases it was not possible to determine accurately the point pHiep but it is known, that it is smaller than 4. Carbonate ions incorporated into hydroxyapatite cause insignificant increase of the $\zeta$ potential and surface charge density in the studied $\mathrm{pH}$ range, probably due to appearance of more acidic carbonate groups in the place of hydroxyl ones.

\section{Acknowledgments}

The research leading to these results has received funding from the People Programme (Marie Curie Actions) of the European Union's Seventh Framework Programme FP7/2007-2013/ under REA grant agreement $n^{\circ}$ PIRSESGA-2013-612484.

\section{REFERENCES}

1. Ching Kee, C., Ismail, H., Mohd, A.F. Effect of Synthesis Technique and Carbonate Content on the Crystallinity and Morphology of Carbonated Hydroxyapatite Journal Material Science Technology 29 (8) 2013: pp. 761-764.

2. Morgan, E.F., $\quad$ Yetkinler, D.N., $\quad$ Constantz, B.R., Dauskardt, R.H. Mechanical Properties of Carbonated Apatite Bone Mineral Substitute: Strength, Fracture and Fatigue Behavior Journal Material Science Technology 8 1997: pp. $559-570$.

3. Lafon, J.P., Championa, E., Bernache-Assollant, D. Processing Of AB-Type Carbonated Hydroxyapatite $\mathrm{Ca}_{10}-\mathrm{X}\left(\mathrm{PO}_{4}\right)_{6}-\mathrm{X}\left(\mathrm{CO}_{3}\right) \mathrm{X}(\mathrm{OH})_{2}-\mathrm{X}-2 \mathrm{y}\left(\mathrm{CO}_{3}\right) \mathrm{Y}$ Ceramics With Controlled Composition Journal European Ceramic Society 28 2008: pp. 139-147.

http://dx.doi.org/10.1016/j.jeurceramsoc.2007.06.009

4. Lee, Y., Min Hahm, Y., Matsuya, S., Nakagaw, M., Ishikawa, K. Characterization of Macroporous CarbonateSubstituted Hydroxyapatite Bodies Prepared in Different Phosphate Solutions Journal of Materials Science 42 2007: pp. $7843-7849$.

5. Peroosa, S., Dub, Z., de Leeuw, N.H. A Computer Modelling Study of the Uptake Structure and Distribution of Carbonate Defects in Hydroxyapatite Biomaterials 27 2006: pp. 2150-2161.

6. Garskaite, E., Gross, K.A., $\quad$ Yang, S.W., $\quad$ Yang, T.C.K., Yang, J.C., Kareiva, A. Effect of Processing Conditions on the Crystallinity and Structure of Carbonated Calcium Hydroxyapatite (CHAp) CrystEngComm 16 2014: pp. 3950-3959. http://dx.doi.org/10.1039/c4ce00119b

7. Dean-Mo, L. Fabrication and Characterization of Porous Hydroxyapatite Granules Biomaterials 17 1996: pp. $1955-1957$.

8. Randolph, A.D., Larson, M.A. Theory of Particulate Processes, second ed. Academic Press, NY, 1986.

9. Janusz, W., Skwarek, E., Zlotucha, A., Reszka, M. The Electrical Double Layer at the Hydroxyapatite/ $\mathrm{NaClO}_{4}$ Solution Interface Polish Journal of Chemistry $82(1-2)$ 2008: pp. $57-67$.

10. Skwarek, E., Janusz, W., Sternik, D. Adsorption of Citrate Ions on Hydroxyapatite Synthetized Journal of Radioanalytical and Nuclear Chemistry 299 (3) 2014: pp. $2027-2036$. http://dx.doi.org/10.1007/s10967-013-2825-z

11. Skwarek, E. Adsorption of Zn on Synthetic Hydroxyapatite from Aqueous Solution Separation Science and Technology 49 (11) 2014: pp. $1654-1662$. 